\title{
Effect of aerated concrete blockwork joints on the heat transfer performance uniformity
}

\author{
Viktor Pukhkal ${ }^{1}$ and Vera Murgul ${ }^{2,3 *}$ \\ ${ }^{1}$ Saint Petersburg State University of Architecture and Civil Engineering, Vtoraya Krasnoarmeiskaya \\ str. 4. St. Petersburg, 190005, Russia \\ ${ }^{2}$ Peter the Great St.Petersburg Polytechnic University, Polytechnicheskaya, 29, St. Petersburg, \\ 195251, Russia \\ ${ }^{3}$ Moscow State University of Civil Engineering, Yaroslavskoe shosse, 26, Moscow, 129337, Russia
}

\begin{abstract}
Analysis of data on the effect of joints of the aerated concrete blocks on the heat transfer uniformity of exterior walls was carried out. It was concluded, that the values of the heat transfer performance uniformity factor in the literature sources were obtained for the regular fragment of a wall construction by approximate addition of thermal conductivities. Heat flow patterns for the aerated concrete exterior walls amid different values of the thermal conductivity factors and design ambient air temperature of -26 ${ }^{\circ} \mathrm{C}$ were calculated with the use of "ELCUT" software for modelling of thermal patterns by finite element method. There were defined the values for the heat transfer performance uniformity factor, reduced total thermal resistance and heat-flux density for the exterior walls. The calculated values of the heat transfer performance uniformity factors, as a function of the coefficient of thermal conductivity of aerated concrete blocks, differ from the known data by a more rigorous thermal and physical substantiation.
\end{abstract}

\section{Introduction}

Wall unreinforced products made of autoclaved aerated concrete have a number of advantages that have determined their wide use in Russia [1, 2]:

- availability of raw components;

- low fire hazard and high fire resistance;

- high accuracy of overall dimensions;

- Technological masonry and high productivity of work;

- low cost of products.

It is necessary to take into account the factors that affect the thermal performance of these products in order to effectively use them in the construction of buildings meeting the requirements of energy efficiency. One of these factors, characterizing the efficiency of insulation, is the heat transfer performance uniformity factor for the enclosing structures [3, 4]:

* Corresponding author: vera.murgul@mail.ru 


$$
r=\frac{R_{0}^{r}}{R_{0}^{r e s}},
$$

where $R_{0}^{r}$ is the reduced total thermal resistance of the section of the enclosing structure, $\left(\mathrm{m}^{2} \cdot{ }^{\circ} \mathrm{C}\right) / \mathrm{W} ; R_{0}^{\text {res }}$ - thermal resistance of a section of a homogeneous enclosing structure, $\left(\mathrm{m}^{2} \cdot{ }^{\circ} \mathrm{C}\right) / \mathrm{W}$.

For example, consider the thermal imaging survey of an energy-efficient demonstration multi-apartment residential building (Building 5, Mebelnaya St., Porkhov, Pskov Region [1, 2]), which is constructed of aerated concrete blocks of D500 density and $375 \mathrm{~mm}$ thick. The survey revealed the influence of block joints on the uniformity of the heat flow field on the surface of the outer wall (Figure 1).
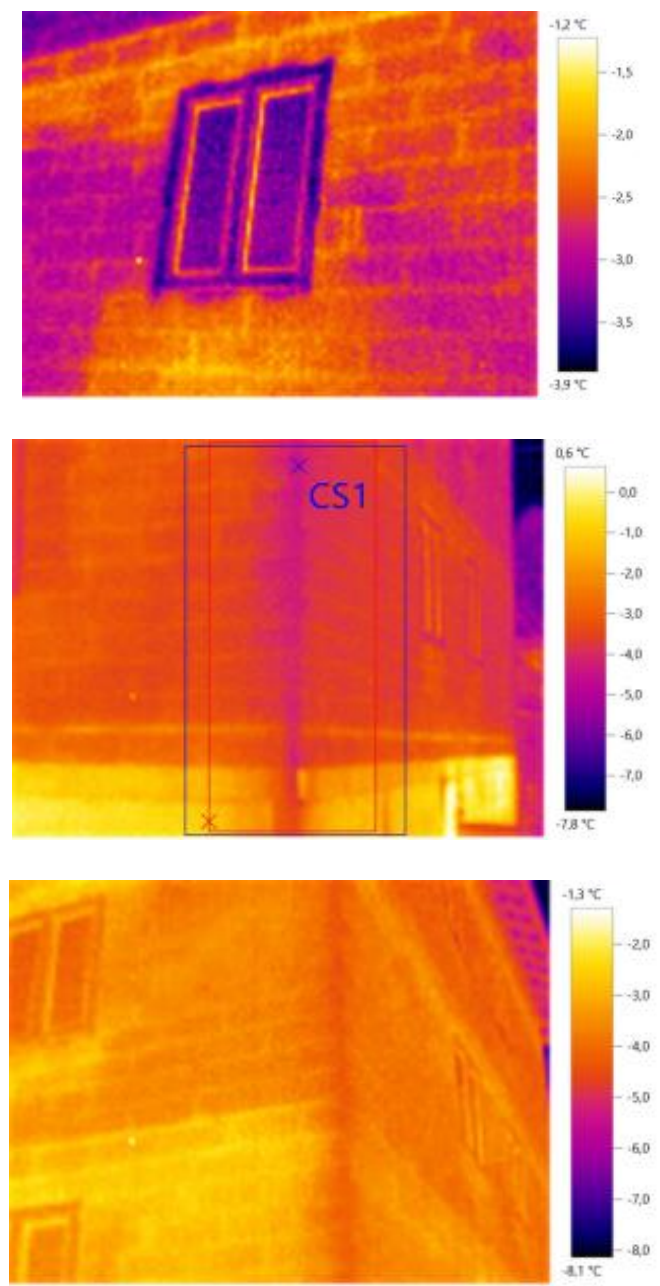
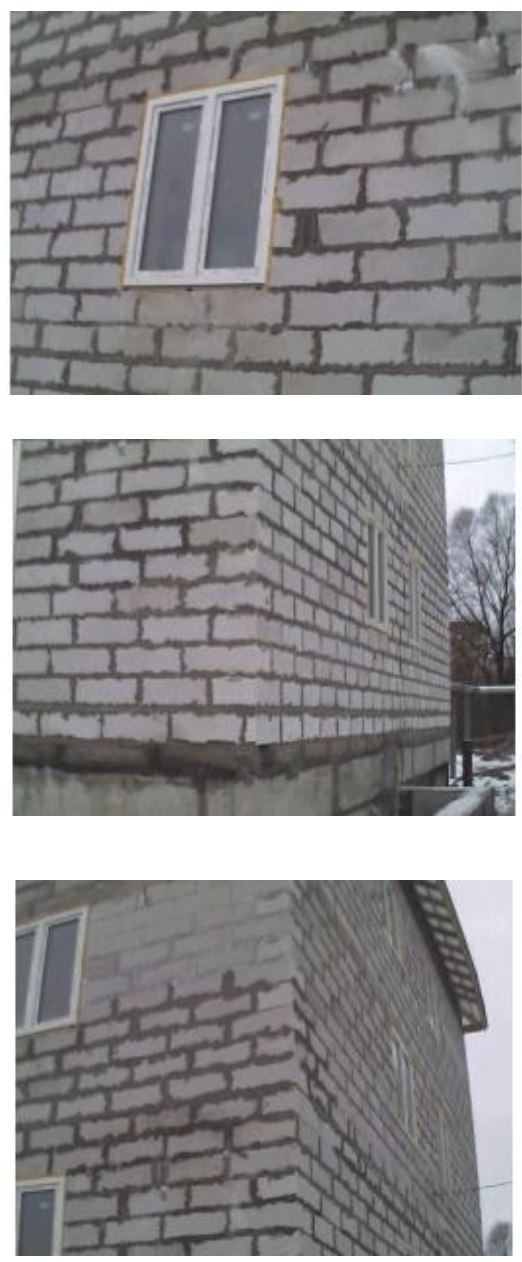

Fig. 1. Heat-conducting inclusions of aerated concrete blockworks in the form of joints

In [5-13], a significant heat transfer heterogeneity of aerated concrete blockwork is indicated. Data on the heat transfer uniformity factors are given for masonry of walls from solid-walled unreinforced products made of autoclaved aerated concrete with a blockwork 
size of $625 \times 250 \mathrm{~mm}[6,9]$. Whereas, the calculation of the heat transfer uniformity factor is performed for a regular fragment of the wall structure by the addition of thermal conductivity.

The reduced total thermal resistance to heat transfer of a regular fragment of the enclosing structure is defined by the approximate dependence [3]:

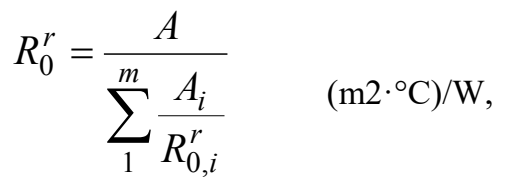

where $A$ is the total area of the characteristic part of the enclosing structure, that equals to the sum of the areas of individual sections, $\mathrm{m}^{2} ; A_{i}$ - the area of the $\mathrm{i}$-th section of the characteristic part of the enclosing structure, $\mathrm{m}^{2} ; R_{0, i}^{r}$ - reduced total thermal resistance to the heat transfer of the $\mathrm{i}$-th section of the characteristic part of the enclosing structure, $\left(\mathrm{m}^{2} \cdot{ }^{\circ} \mathrm{C}\right) / \mathrm{W}$.

Water content of aerated concrete products proves to be higher during the operation of buildings than the design one, at which the thermophysical characteristics of the materials in [3] are given, and the values of the thermal conductivity factors for the products will be 2-3 times higher $[5,7,8]$.

The use of approximate methods to calculate the heat transfer performance uniformity factor requires specification of the data. In addition, the maximum value of the thermal conductivity of aerated concrete blocks to determine the heat transfer performance uniformity factor is limited to $0.208 \mathrm{~W} /\left(\mathrm{m} \cdot{ }^{\circ} \mathrm{C}\right)$.

\section{Materials and Methods}

The heat transfer uniformity factor of the enclosing structure can be defined on the basis of calculation of the heat flow field of the structure. Consider the two-dimensional heat flow field of structure of the exterior wall, which is made of aerated concrete blocks with the initial data according to $[1,2]$ :

- design ambient air temperature - minus $26^{\circ} \mathrm{C}$;

- design internal air temperature - plus $20^{\circ} \mathrm{C}$;

- the exterior wall is made of aerated concrete blocks of D500 density and $375 \mathrm{~mm}$ thick;

- the thickness of the horizontal and vertical blockwork joints is $10 \mathrm{~mm}$.

A sand-cement mortar with a density of $1800 \mathrm{~kg} / \mathrm{m}^{3}$ (thermal conductivity factor under operating conditions of the fencing $\left.\mathrm{B}[3]-\lambda_{\mathrm{m}}=0.93 \mathrm{~W} /\left(\mathrm{m} \cdot{ }^{\circ} \mathrm{C}\right)\right)$ is used for brickwork.

The factor of thermal conductivity for the blocks $\left(\lambda_{b}, \mathrm{~W} /\left(\mathrm{m} \cdot{ }^{\circ} \mathrm{C}\right)\right)$ is assumed for the operating conditions B according to [8].

Calculation of the temperature field and heat fluxes of the external wall structure is carried out in the "ELCUT" software, where two-dimensional thermal fields are modelled.

The reduced total thermal resistance of a regular fragment of the enclosing structure is determined from the dependence:

$$
R_{0}^{r}=\frac{t_{\text {int }}-t_{\text {ext }}}{q}, \cdot\left(\mathrm{m}^{\left.2 \cdot{ }^{\circ} \mathrm{C}\right) / \mathrm{W},}\right.
$$

where $t_{\text {int }}$ is the internal air temperature, ${ }^{\circ} \mathrm{C} ; t_{\text {ext }}$ is the ambient air temperature, ${ }^{\circ} \mathrm{C} ; q$ is the heat flux density for a regular fragment of the enclosing structure, $\mathrm{W} / \mathrm{m}^{2}$.

Design thermal resistance to heat transfer of a homogeneous enclosing structure [3] is: 


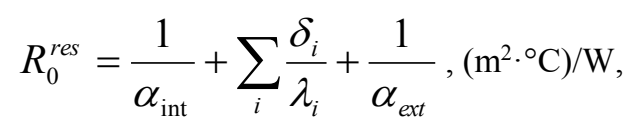

where $\alpha_{\text {int }}=8.7 \mathrm{~W} /\left(\mathrm{m}^{2} \cdot{ }^{\circ} \mathrm{C}\right)$ is the heat transfer coefficient of the inner surface of the enclosing structure [3]; $\alpha_{\text {ext }}=23 \mathrm{~W} /\left(\mathrm{m}^{2} \cdot{ }^{\circ} \mathrm{C}\right)$ is the heat transfer coefficient of the outer surface of the enclosing structure [3]; $\delta_{i}$ is thickness of the i-th layer of the enclosing structure, $\mathrm{m} ; \lambda_{i}$ is the thermal conductivity factor of the $\mathrm{i}$-th layer of the enclosing structure, $\mathrm{W} /\left(\mathrm{m} \cdot{ }^{\circ} \mathrm{C}\right)$.

\section{Results}

The heat flow fields of the exterior wall were calculated with the use of "ELCUT" software in the range of the thermal conductivity factor for aerated concrete blocks from 0.088 (block $\mathrm{D} 300$ - [1] $)$ to $0.6 \mathrm{~W} /\left(\mathrm{m} \cdot{ }^{\circ} \mathrm{C}\right)$. Example of calculation results is presented in Figure 2 in the form of heat flow fields and heat flux densities under design conditions.

a) heat flow field

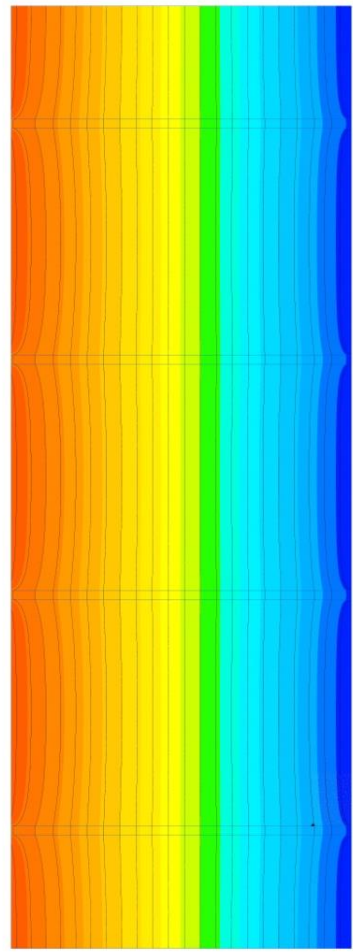

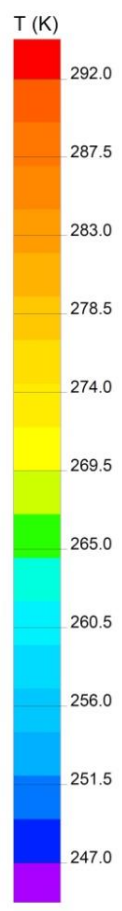

b) heat flux density

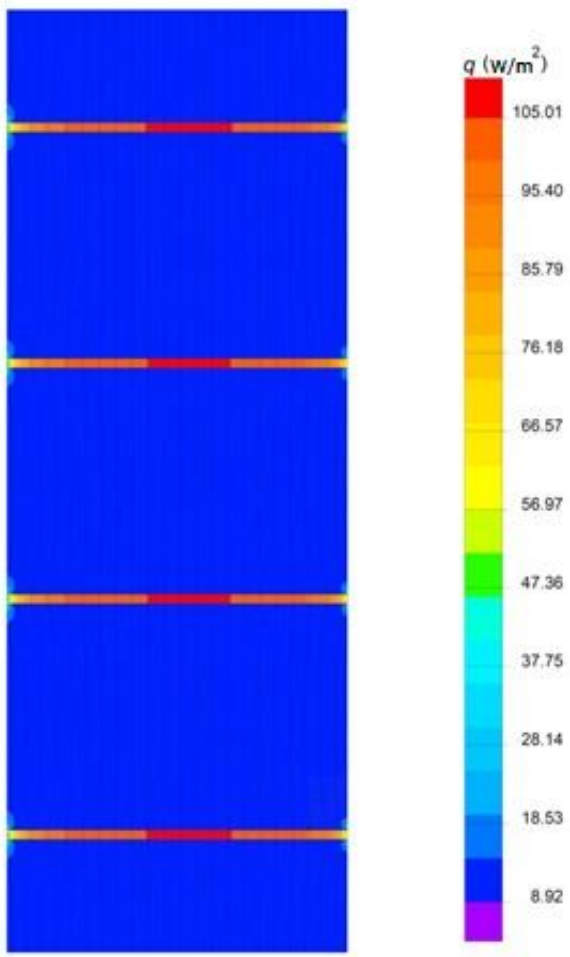

Fig. 2. Calculation example of the heat flow field and the heat flux density of the exterior wall made of aerated concrete blocks of D300 density

According to the calculations, the heat flux density through the enclosing structure and its thermal resistance are determined depending on the thermal conductivity factor of the aerated 
concrete blocks (Table 1). For comparison, data for a homogeneous structure are given (without taking into account the blockwork joints).

Table 1. Heat flux density through the aerated concrete blockworks and thermal resistance to heat transfer of the structure

\begin{tabular}{|c|c|c|c|c|}
\hline \multirow{2}{*}{$\begin{array}{c}\text { Thermal } \\
\text { conductivity factor } \\
\text { of the block, } \lambda_{i} \text {, } \\
\mathrm{W} /\left(\mathrm{m} \cdot{ }^{\circ} \mathrm{C}\right)\end{array}$} & \multicolumn{2}{|c|}{ Heat flux density, $q_{i}$, W/m² } & \multicolumn{2}{|c|}{ Thermal resistance, $\left(\mathrm{m}^{2} \cdot{ }^{\circ} \mathrm{C}\right) / \mathrm{W}$} \\
\hline & $\begin{array}{l}\text { homogeneous } \\
\text { structure }\end{array}$ & blockwork & $\begin{array}{l}\text { homogeneous } \\
\text { structure, } R_{0}^{\text {res }}\end{array}$ & reduced, $R_{0}^{r}$ \\
\hline 0.088 & 10.408 & 14.302 & 4.420 & 3.216 \\
\hline 0.117 & 13.676 & 17.581 & 3.364 & 2.616 \\
\hline 0.147 & 16.978 & 20.870 & 2.709 & 2.204 \\
\hline 0.183 & 20.837 & 24.700 & 2.208 & 1.862 \\
\hline 0.208 & 23.454 & 27.291 & 1.961 & 1.686 \\
\hline 0.3 & 32.661 & 36.391 & 1.408 & 1.264 \\
\hline 0.4 & 41.974 & 45.590 & 1.096 & 1.009 \\
\hline 0.5 & 50.637 & 54.153 & 0.908 & 0.849 \\
\hline 0.6 & 58.717 & 62.150 & 0.783 & 0.740 \\
\hline
\end{tabular}

\section{Discussion}

According to the calculation given in Table 1, the values of the heat transfer performance uniformity factors of the enclosing structure are determined depending on the thermal conductivity factor of the aerated concrete blocks (Figure 3 ).

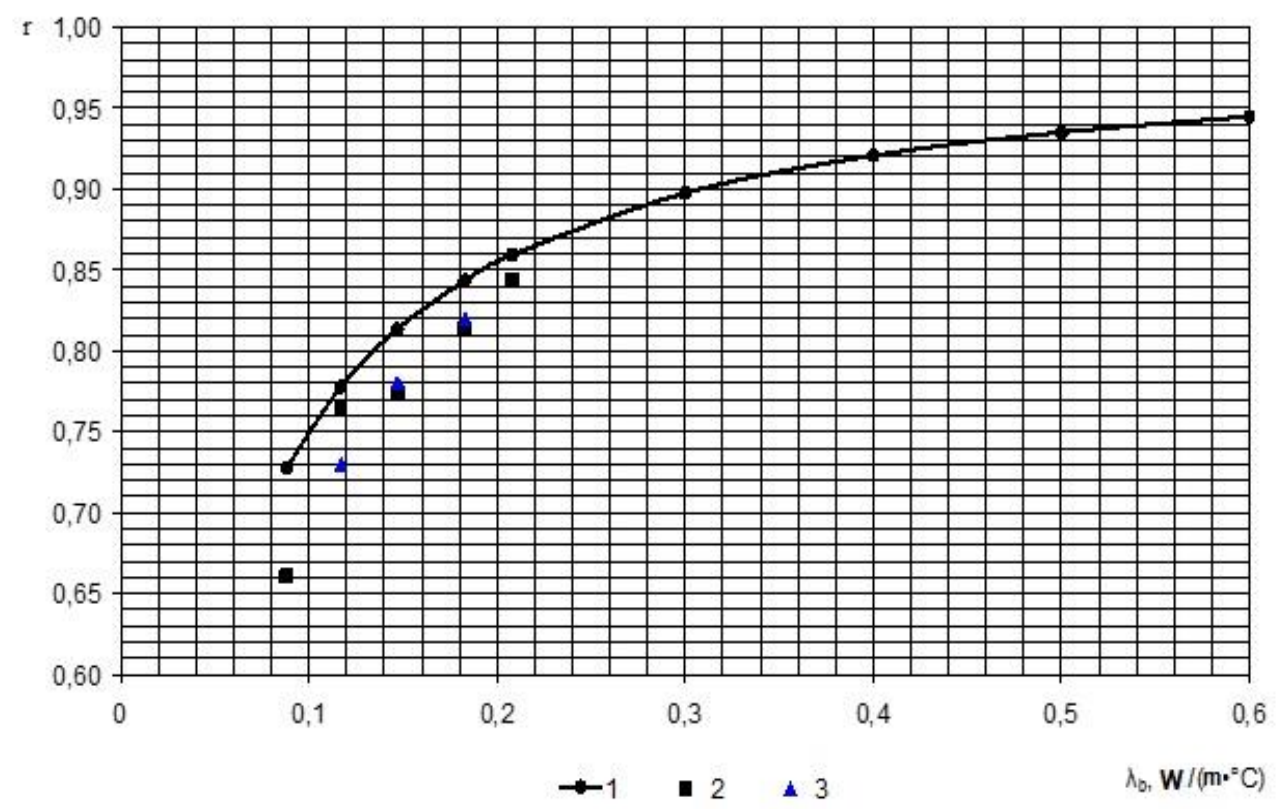

Fig. 3. Dependence of the heat transfer performance uniformity factor on the thermal conductivity factor of aerated concrete blocks: 1 - calculation results; 2 - data [9]; 3 - data [6]

As it follows from the performed calculations, an increase in the thermal conductivity factor (density) of aerated concrete blocks leads to an increase in the factor of 
heat transfer performance uniformity. The calculation results differ (up to 10\%) from the values that are indicated in the literature $[6,9]$.

The relationship between the thermal conductivity factor of the joints material and aerated concrete blocks has a determining effect on the values of the heat transfer uniformity factor of the blockwork for a given thickness of the joints (Figure 4).

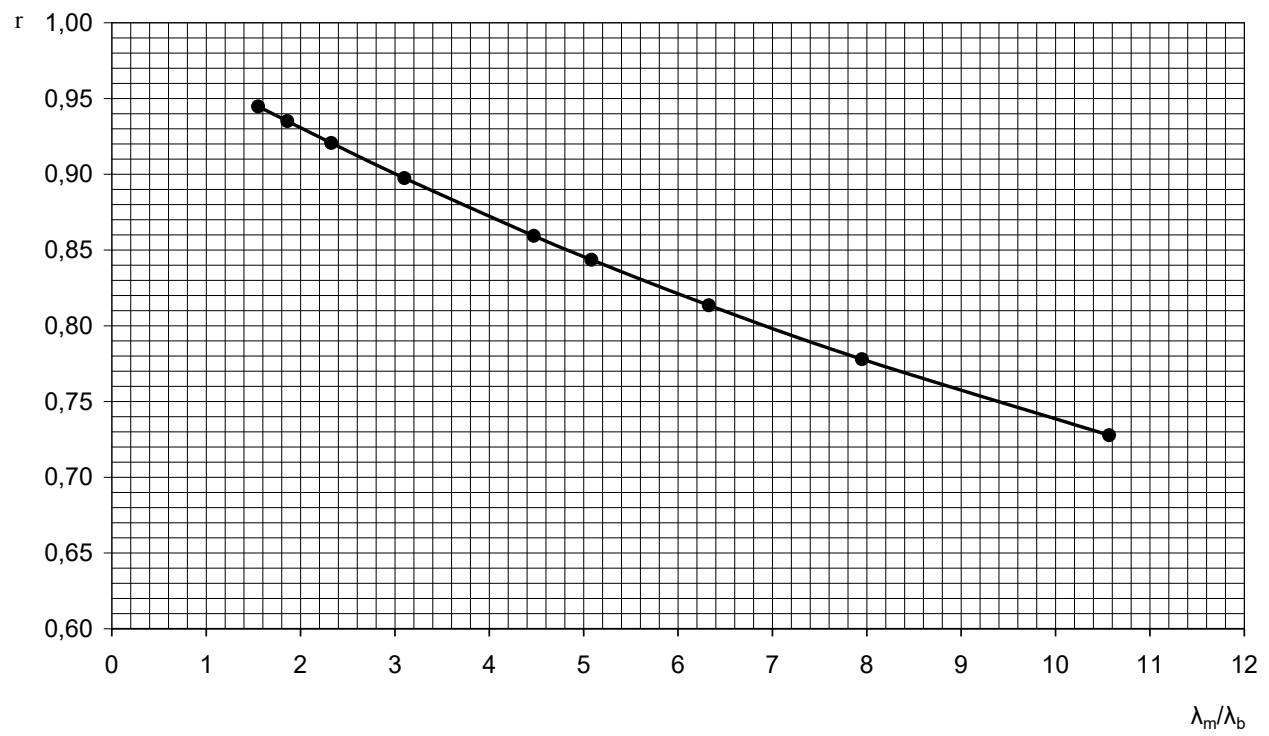

Fig. 4. Dependence of the heat transfer performance uniformity factor on the ratio of the thermal conductivity factors of the joints material and aerated concrete blocks

It is necessary to develop clamping compounds that are characterized by low values of the thermal conductivity factors in order to further improve the aerated concrete blockworks, when ensuring the required adhesion between the blocks and not impairing the performance of the enclosing structures in strength, stability, crack resistance, fire resistance, etc.

\section{Conclusions}

1. Design values of the heat transfer performance uniformity factor of the exterior walls of buildings made of aerated concrete can be determined using the "ELCUT" finite element modelling software, which is especially important at the stage of simulating various design solutions.

2. The calculation of the thermal state of the exterior enclosing structures out of aerated concrete and the calculated values of the heat transfer performance uniformity factor, depending on the thermal conductivity factor of the aerated concrete blocks, differ from the known data by a more rigorous thermophysical substantiation.

\section{References}

1. A. S. Gorshkov, P. A. Muravyev, A.V. Tarakin, Energosberezheniye, 8, 30-34 (2016)

2. Muravyev P.A., Lukina-Lebedeva M.A., Tarakin A. V., Gorshkov A.S. Energoeffektivnyy demonstratsionnyy zhiloy dom, realizuyemyy po programme PROON-GEF v g. Porkhove. Inzhenernyye sistemy, № 4. 2016. S. 34-45. 
3. Russian State Standard SP 50.13330.2012.

4. Russian State Standard RMD 23-16-2012

5. A.B. Krutilin, YU. A. Rykhlenok, V.V. Leshkevich, Magazine of Civil Engineering, 2(54), 46-55 (2015)

6. A.S. Gorshkov, A.A. Gladkikh, Magazine of Civil Engineering, 3(13) 39-42 (2010)

7. V.A. Pinsker, V.P. Vylegzhanin, G.I. Grinfel'd, Magazine of Civil Engineering, 8(10) 17-19 (2009)

8. N.I. Vatin, A.S. Gorshkov, S.V. Korniyenko, I.I. Pestryakov, Construction of Unique Buildings and Structures, 1(40), 78-101. (2016)

9. URL: http://www.hplush.ru/library

10. URL: https://elcut.ru/demo/manual.pdf

11. A. Solovyev, A. Pustovgar, A. Adamtsevich, L. Shilova, K. Degtyarev, D. Solovyev, Journal of Applied Engineering Science, 15, 360- 370 (2017) DOI -10.5937/jaes1514950

12. A.O. Adamtsevich, A.P. Pustovgar, S.A. Pashkevich, A.V. Eremin, Int. Journal of Applied Engineering Research, 11, 1609 - 1611 (2016)

13. A. Solovyev, A. Pustovgar, L. Shilova, A. Adamtsevich, D. Solovev, Procedia Engineering, 165, 1275 - 1280 (2016) DOI- 10.1016/j.proeng.2016.11.850 